\title{
Structural Health Monitoring for Reinforced Concrete Containment Using Inner Electrical Resistivity Method
}

\author{
Mostafa Hassaan, Mohamed Ihab Elmasry, Nabil El Ashkar \\ Construction and Building Engineering Department, Arab Academy for Science, Technology and Maritime Transport, \\ Alexandria, Egypt \\ Email: mostafa.hassan@ryerson.ca
}

How to cite this paper: Hassaan, M., Elmasry, M.I. and El Ashkar, N. (2021) Structural Health Monitoring for Reinforced Concrete Containment Using Inner Electrical Resistivity Method. Open Journal of Civil Engineering, 11, 317-341. https://doi.org/10.4236/ojce.2021.113019

Received: August 21, 2021

Accepted: September 11, 2021

Published: September 14, 2021

Copyright (c) 2021 by author(s) and Scientific Research Publishing Inc. This work is licensed under the Creative Commons Attribution International License (CC BY 4.0).

http://creativecommons.org/licenses/by/4.0/

\begin{abstract}
Nuclear power plants (NPPs) are considered as the main source for generating electricity nowadays in some countries. The effect of impact of heavy fully loaded aeroplane such as (Boeing 747-200c) causes leakage of the radiation through the cracks generated on the external RC containment of NPPs, and this leads to severe damage for humans and cities. In this research paper, external RC containment is modeled using ANSYS and hit by Boeing 747-200c which is the heavier aeroplane compared to other jets and causes severe damage for external RC containment. In addition, the impact location for Boeing 747-200c is considered at $30 \mathrm{~m}$ vertical height. RC containment response was studied after the impact of an aeroplane and a proposed structural health monitoring technique is applied using embedded sensors in order to detect and locate the embedded cracks that is generated due to the effect of impact of heavy aeroplane. It was concluded that RC containment is intact except for the impact region which is damaged. An experimental program was applied on a part of the element in ANSYS which is away from the impact region. Four specimens were cast using heavy weight concrete in laboratory. Three cracked specimens consist of different lengths of vertical cracks which represent different times of impact in order to replicate crack propagation as in ANSYS. The cracks are simulated inside laboratory specimens using failure criteria. The parameters used in detecting the cracks for specimens are the percentage change in electrical resistivity and Decimal Logarithm Resistivity Anisotropy (DLRA) at which they give a good indication for the presence of the crack.
\end{abstract}

\section{Keywords}

Reinforced Concrete Containment, Structural Health Monitoring, Electrical Resistivity 


\section{Introduction}

Structural Health Monitoring (SHM) is defined as monitoring the integrity of structures and detecting the damage in real-time. There are different techniques which can assess the health monitoring of RC structures using different tools such as dynamic response measurements, strain variations and variations in electrical resistivity in concrete. Electrical resistivity measurements measure the damage propagation in concrete and the corrosion of steel reinforcement [1]. Structural health monitoring is continuous real-time data which are collected for studying the damage propagation in RC structures. Moreover, electrical resistivity is considered as a non-destructive testing method for Reinforced Concrete (RC) elements and can be used in detecting cracks [2] [3]. Therefore, electrical conductivity can be used to detect and monitor crack initiation and propagation in concrete [2]. The advantages of the electrical resistivity testing technique are considered low in cost, simple and efficient. In general, electrical resistivity of concrete is related to the microstructure of the cement matrix, its pore structure and pore size distribution [4]. In concrete, the current flows through the pore liquid in the cement paste [5]. Moreover, conduction of electricity through concrete may take place in two ways, electronic and electrolytic. Electrolytic conduction occurs by motion of ions in concrete inside the pore solution whereas the electronic conduction occurs through the motion of free electrons in the conductive media. Thus, concrete electrical resistivity is a geometry independent material property that describes the electrical resistance, the ratio between the applied voltage and the resulting current in unit cell geometry [6].

Several methods for measuring electrical resistivity were mentioned in this literature [7]. Wenner probe method is the widely used reliable method [7] [8] for measuring electrical resistivity. The factors that control electrical resistivity features in concrete are the hydration degree of the cement paste of concrete which would result in an increase of electrical resistivity with respect to time. Moreover, other influential factors affecting electrical resistivity measurements include the relative humidity, the concrete temperature, and the ions concentration and their mobility in the pore solution [9]. The electrical resistivity of concrete can be measured using several methods [10]. Typically, electrodes are placed on the surface and the resistance is measured as in Wenner test. The resistivity is often related to corrosion and durability performance of concrete [11].

\subsection{Methods of Measuring Electrical Resistivity for Concrete}

\subsubsection{Two-Plate Electrode Method}

Figure 1 describes the method application for two plate electrode method. During testing, a low frequency electrical current passes between the two plates through the entire specimen while the voltage drop is measured as shown in Figure 1 [12]. The electrical resistivity for two plate electrode method is calculated from Equation (1). 


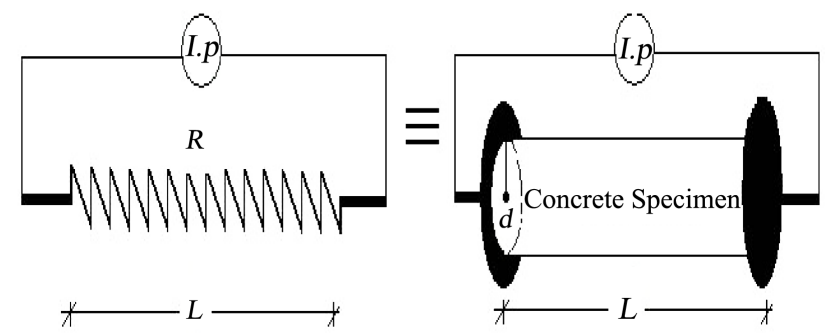

Figure 1. Concrete bulk electrical resistivity test with two plates [9].

$$
\rho=\frac{R A}{L}
$$

\subsubsection{Four-Point Electrode Method (Wenner Configuration Method)}

The four-point electrode method is currently the most widely used technique for field concrete resistivity measurements. During testing, a low frequency alternating current is applied between the two outer electrodes while the voltage drop is measured between two inner electrodes [7] as shown in Figure 2. The electrical resistivity for four-point electrode method is calculated from Equation (2).

$$
\rho=2 \Pi \times a \times R
$$

\subsubsection{Four Probe Square Configuration}

In this technique, the four probes are arranged in a square pattern as shown in Figure 3 on the outer surface of concrete, and the electrical resistivity measurement for four probe square configuration can be calculated from Equation (3).

$$
\rho=\frac{2 \times \Pi \times a \times R}{2-\sqrt{2}}
$$

\subsubsection{Embedded Electrode Configuration}

\section{1) Linear Inner Electrical Resistivity Measurement (LIERM)}

In this technique, four probes are arranged on the same line pattern inside the concrete, as shown in Figure 4. Electrical resistivity for (LIERM) can be calculated from Equation (4) [13].

$$
\rho=4 \times \Pi \times a \times R
$$

\section{2) Square Inner Electrical Resistivity Measurement (SIERM)}

In this technique, four probes are arranged on a square pattern inside the concrete, as shown in Figure 5, and electrical resistivity for (SIERM) can be calculated from Equation (5) [3].

$$
\rho=\frac{4 \times \Pi \times a \times R}{2-\sqrt{2}}
$$

where: $\rho$ : electrical resistivity $(\mathrm{ohm} \cdot \mathrm{m})$, a: electrode spacing $(\mathrm{m}), R$ : electrical current resistance (ohm), and $A$ : cross section area of specimen.

Generally, there are two studied parameters that can be based on electrical resistivity measurements in detecting damage,

a) Percentage of change in electrical resistivity (\% change): 


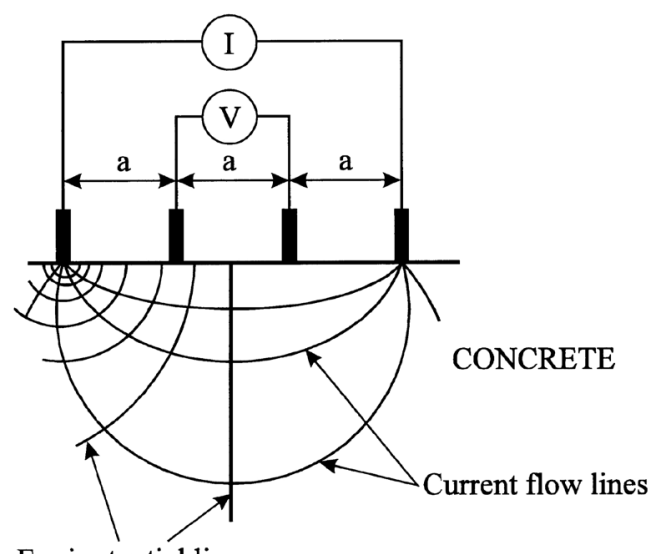

Equipotential lines

$$
\text { Resistivity }(\rho)=2 \pi \frac{\mathrm{a}}{\mathrm{I}}
$$

Figure 2. Four-electrode resistivity test (Wenner method) [7].

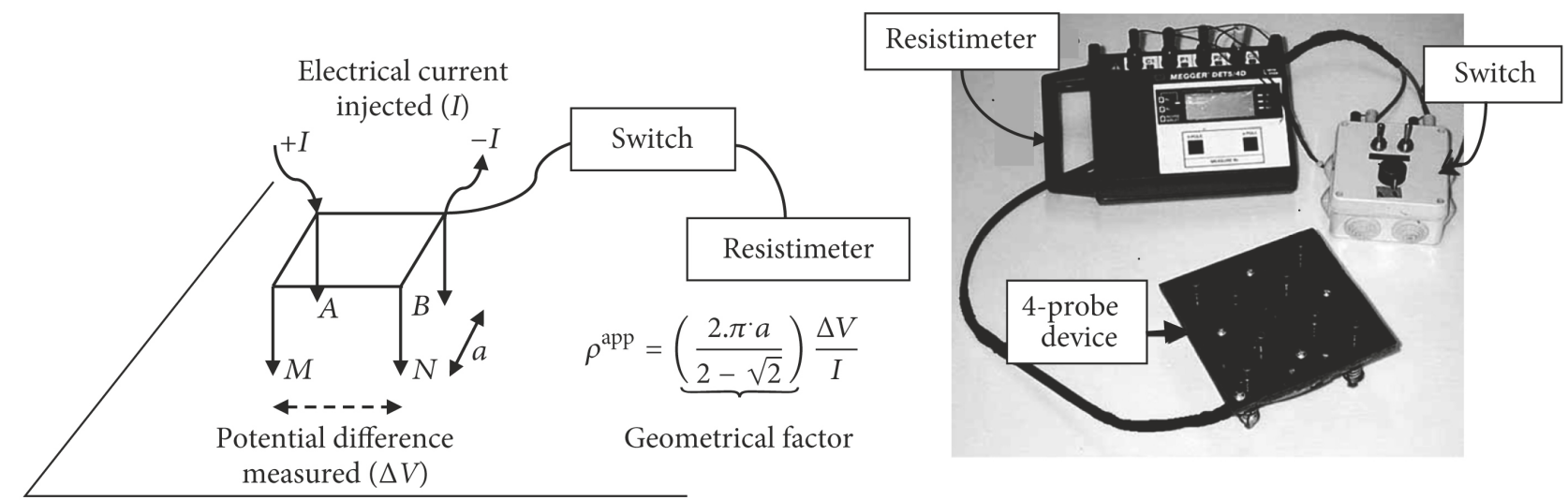

Figure 3. Four probe square array principle [1].
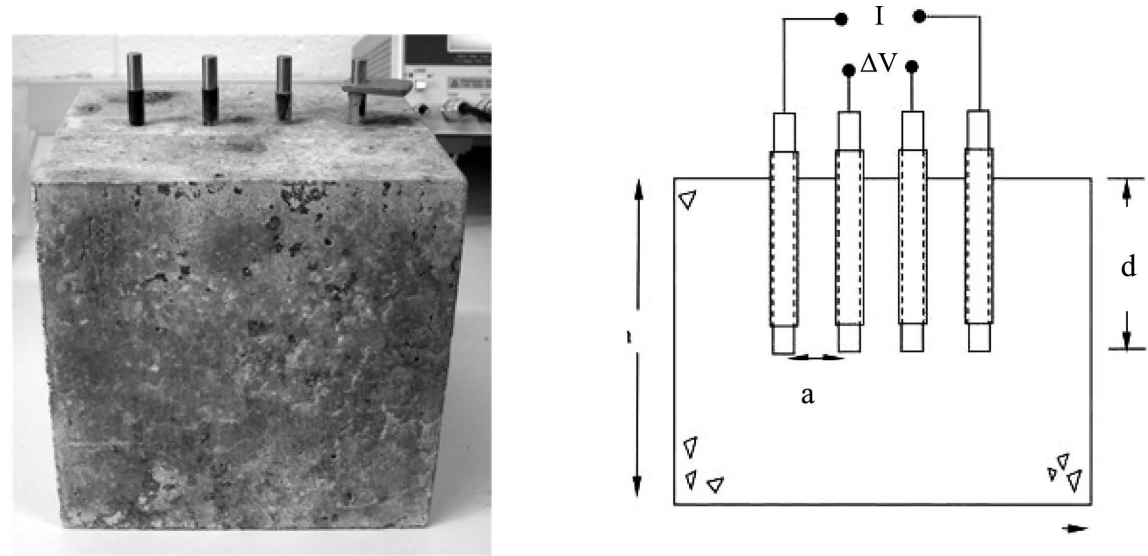

Figure 4. Concrete specimens with embedded electrodes [13].

This can be calculated from Equation (6) [2],

$$
\% \text { change }=\frac{R_{p}-R_{r}}{R_{r}} \times 100
$$




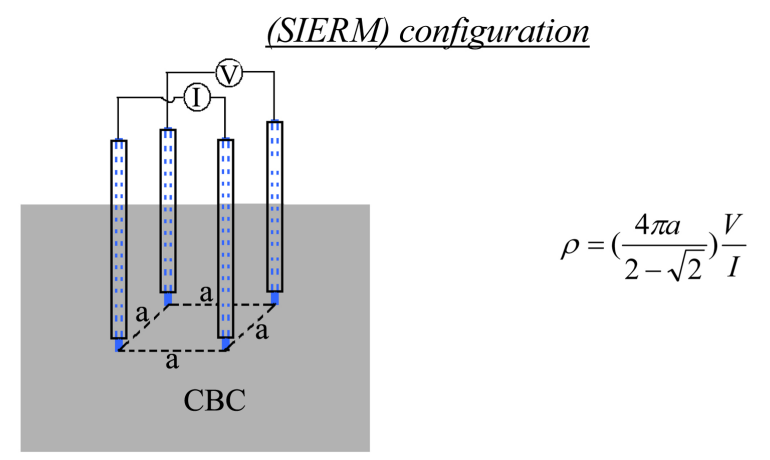

Note: $\rho$ is the electrical resistivity, $a$ is the spacing between probes, $V$ is the voltage and $I$ is the electrical current

Figure 5. SIERM configuration [3].

where: $R_{p}$ : resistivity at any location, and $R_{r}$ : reference resistivity.

b) Decimal Logarithmic Resistivity Anisotropy (DLRA):

(DLRA) can be calculated from Equation (7) [2]

$$
D L R A=\log _{10} \frac{R_{v}}{R_{h}} \text { or } D L R A=\log _{10} \frac{R_{h}}{R_{v}}
$$

where: $R_{r}$ : resistivity at vertical current direction, $R_{h}$ : resistivity at horizontal current direction.

The change in electrical resistivity would indicate a crack. The four probe square measurement device developed by Lataste et al. [1], this device with the square four probes was used for measuring the material electrical anisotropy. Therefore, the percentage change and DLRA can be efficient parameters for detecting cracking. Moreover, reinforced concrete is the most widely used material for reactor shielding in Nuclear Power Plants (NPPs) due to its cheapness and satisfactory mechanical properties. The aggregate component of concrete that contains a mixture of many heavy elements plays an important role in improving concrete shielding properties [14]. Heavyweight concrete is extensively used as a shield in NPPs and radio therapy rooms, and for transporting and storing radioactive wastes [14].

In this research, the proposed structure health monitoring technique which is inner electrical resistivity which is located inside the core of RC wall of the nuclear power plant will give a large information data for every part of the external containment, if the containment suffers from cracks inside the core of $\mathrm{RC}$ wall which can't be seen by visual inspection. Nondestructive testing method (Inner Electrical Resistivity) in this research is distributed through red copper sensors with equal spacing in vertical and circumference direction inside the core of RC wall in two grid layers inside the core of RC wall. The proposed technique will build inside the RC containment during its construction stage which will give full information about the RC containment in real time if there is a change in electrical resistivity. Proposed inner electrical resistivity method is the more accurate method compared to other methods such as two plate electrode method 
[9] [12] or Wenner method [7], because it gives a continuous real time data for the RC wall instead of scanning every part for huge RC containment using any method which depends on taking the measurement on the surface.

\subsection{Problem Definition and Objective for This Study}

This research paper studies the response of damage propagation that is caused by impact of an aeroplane Boeing 747-200c upon a typical outer RC containment of the NPPs. The RC containment was made from heavy weight concrete. The step-by-step nonlinear response of the jet impact is studied then analyzed to identify the propagating damage in the RC containment structure from global and local behavior perspectives. The cracks which are generated on the RC containment due to impact of Boeing 747-200c may lead to the escape of radiation into the external environment. Nondestructive testing measurements were applied on the external RC containment at which sensors were distributed all over the circumference for RC containment and inserted inside the RC core of the wall in order to check the credibility of detecting damage efficiently after the impact of an aeroplane instantaneously.

\section{Numerical Modeling of RC Containment}

\subsection{Modeling of RC Containment}

The typical external RC nuclear containment consists of shell wall; dome and base mat foundation is studied in this research. In this study, the thickness of the shell wall was considered $1.2 \mathrm{~m}$ and the inner side of the external containment was assumed lined with steel liner plate of thickness $9.375 \mathrm{~mm}$ to prevent the escape of radiation into the external environment according to ASCE 58, 1980. The dome thickness was taken $1.05 \mathrm{~m}$ according to ASCE 58 [15] and Czerniewski [16]. The dome is assumed carried by the wall, and the load of the wall is assumed transmitted into the fixed foundation [16]. The inner diameter of the containment was considered $45 \mathrm{~m}$, and the height of the cylindrical wall is nearly $36.45 \mathrm{~m}$ from the top of foundation level. The total height of the containment was considered $60 \mathrm{~m}$ height. In this model, it was considered that the connection between the foundation and the cylindrical wall is fixed. Figure 6 represents a schematic section elevation drawing for the studied RC containment.

The containment was modeled using ANSYS ${ }^{\circ}$. The element used in ANSYS in order to model RC containment is Solid-65. Solid-65 element is used for 3D modeling of solids with or without reinforcing rebar. This solid element is capable of indicating cracking in tension or crushing in compression. The element is defined by eight nodes having three degrees of freedom at each node: translations in the nodal $\mathrm{x}, \mathrm{y}$ and $\mathrm{z}$ directions. In addition, up to three different rebar specifications may be defined for Solid- 65 elements. Moreover, Solid- 45 element is used in defining the inner steel liner plate. The element has plasticity, creep, swelling, stress stiffening, large deflection, and large strain capabilities. 


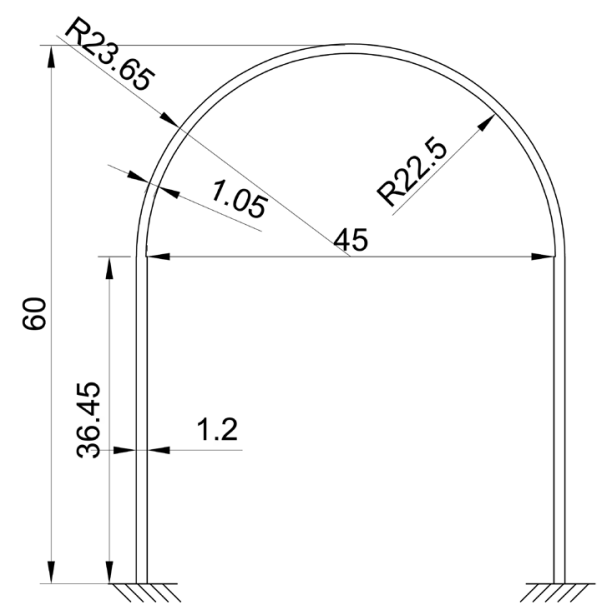

Figure 6. Section elevation for RC containment.

In this model, the reinforcement was considered as membrane layers inside the wall and dome. For each layer, the steel type and the direction of reinforcement are specified. The reinforcement layers were considered continuous along the length of each layer. Reinforcement of the wall in the vertical direction is assumed \#18 spaced at $300 \mathrm{~mm}$, while in the circumference direction, the reinforcement is $2 \# 18$ spaced at $300 \mathrm{~mm}$ as mentioned in ASCE 58 [15] [16]. The element size in this model is $2.068 \mathrm{~m} \times 2.025 \mathrm{~m}$ with different thickness along the width of the wall with acceptable aspect ratio. The total number of elements is 58,830 , and total nodes are 62,082 in this model.

\subsection{Material Modeling of Containment}

Concrete, steel reinforcement and steel liner plate have different material models. The density of heavy concrete was taken $3000 \mathrm{Kg} / \mathrm{m}^{3}$. The concrete was modeled as a multi-linear isotropic hardening plastic material, having its stress strain curve as shown in Figure 7 [17]. The Non-linear curve was obtained from Equation (8) to Equation (12).

$$
\begin{gathered}
f_{c}=E_{c} \mathcal{E} \text { for } 0<\mathcal{E}<\mathcal{E}_{1} \\
f_{c}=f_{c}^{\prime} \text { for } \mathcal{E}_{0}<\mathcal{E}<\mathcal{E}_{c u} \\
f_{c}=\frac{E_{c} \mathcal{E}}{1+\left(\frac{\mathcal{E}}{\mathcal{E}_{0}}\right)^{2}} \text { for } \mathcal{E}_{1}<\mathcal{E}<\mathcal{E}_{0} \\
\mathcal{E}_{1}=\left(0.3 \times f_{c}\right) / E_{c} \\
\mathcal{E}_{0}=2 f_{c} / E_{c}
\end{gathered}
$$

The concrete is modeled in tension as shown in Figure 8 at which the rupture strength of concrete is identified and the cracked strain can be calculated automatically from elastic modulus of concrete. The steel reinforcement bars modeling and inner steel liner plate is assumed to be elastic perfectly plastic as shown in 


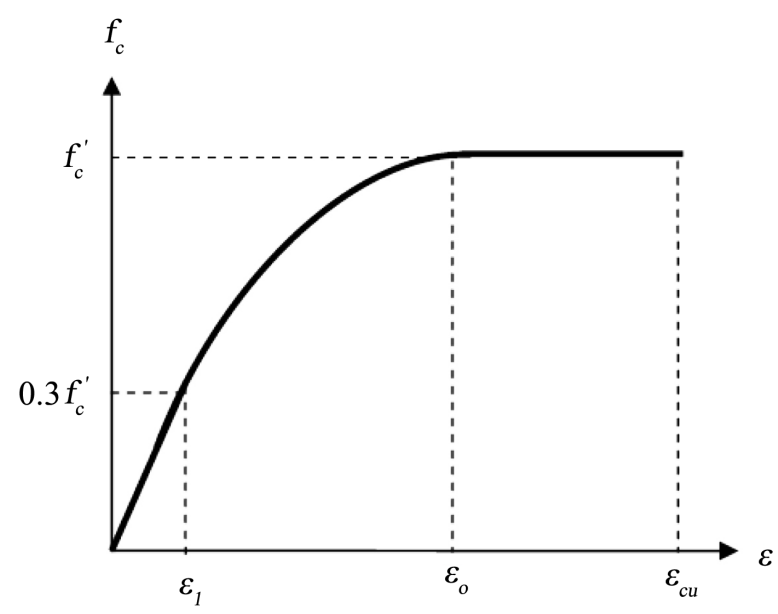

Figure 7. Uniaxial compressive stress strain curve for concrete in compression.

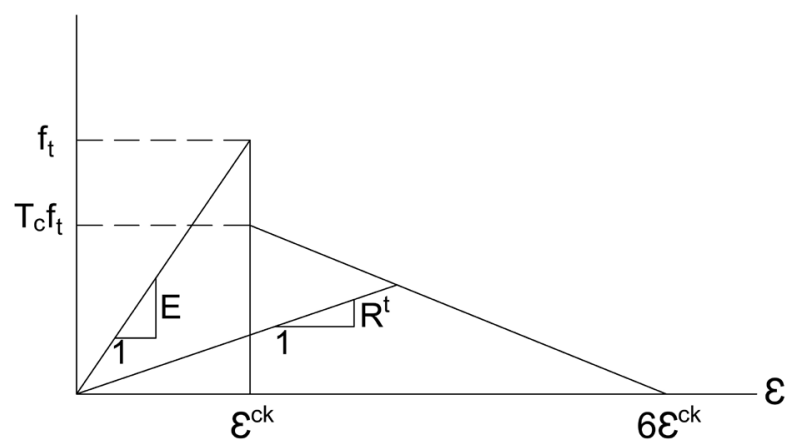

Figure 8. Stress strain curve for concrete in tension.

Figure 9. Its elastic modulus is $2 \mathrm{E} 5 \mathrm{~N} / \mathrm{mm}^{2}$, its Poisson ratio is 0.3 . In addition, the steel reinforcement is treated as bilinear isotropic hardening plastic material with yielding of $400 \mathrm{Mpa}$, whereas yielding for the inner steel liner plate is 165 Mpa according to Teh $\mathrm{Hu}$ and $\mathrm{Xu}$ Lin [18]. The density of steel reinforcement and steel liner plate is considered $7850 \mathrm{Kg} / \mathrm{m}^{3}$. The concrete strength input data which includes the open and closed shear transferee coefficient are defined in Table 1.

\section{Failure Criteria}

The concrete material model predicts the failure of brittle materials. Both cracking and crushing failure modes are accounted for. The criterion for failure of concrete due to a multi-axial stress state can be expressed in the form according to William and Warnke [19] as in Equation (13):

$$
F / f_{c}-s \geq 0
$$

where:

$$
\begin{aligned}
& F=\text { function of the principal stress state }\left(\sigma_{x p}, \sigma_{y p}, \sigma_{z p}\right) ; \\
& s=\text { failure surface expressed in terms of principal stresses; } \\
& f_{c}=\text { uniaxial crushing strength; } \\
& \sigma_{x p}, \sigma_{y p}, \sigma_{z p}=\text { principal stresses in principal directions. }
\end{aligned}
$$




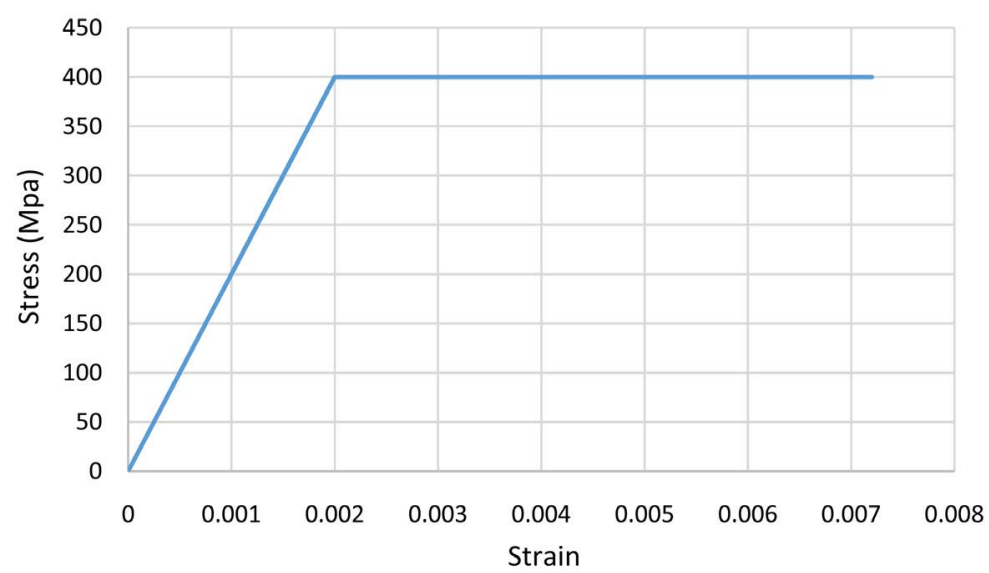

(a)

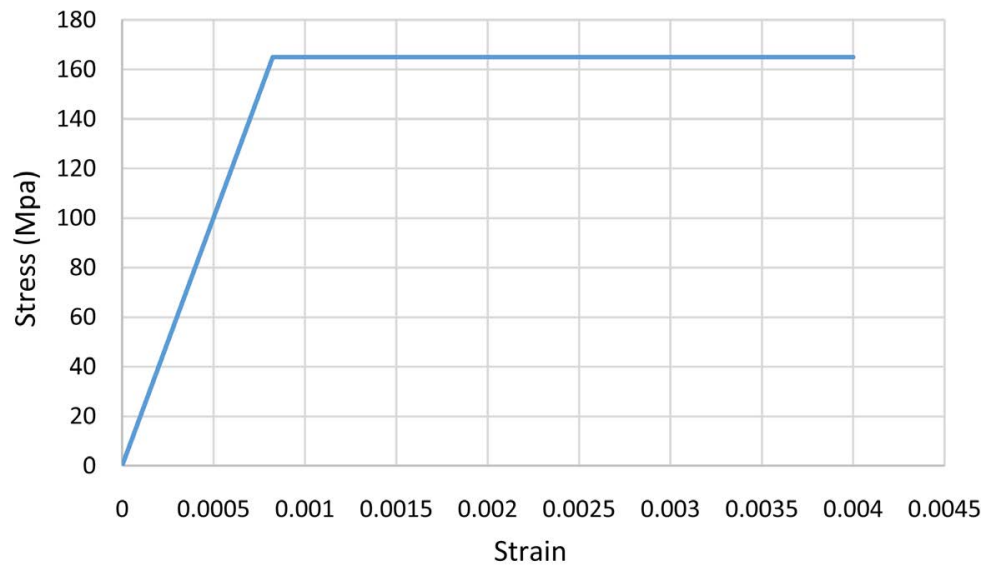

(b)

Figure 9. Stress strain curve for steel reinforcement and inner steel liner plate. (a) Steel reinforcement; (b) Inner steel liner plate.

Table 1. Concrete strength input data.

\begin{tabular}{cc}
\hline Input strength parameters & Values \\
\hline Open shear transfer coefficient & 0.3 \\
Closed shear transfer coefficient & 0.9 \\
Mod. of elasticity of concrete $(\mathrm{MPa})$ & $36,406.043$ \\
Poisson ratio of concrete & 0.2 \\
Uniaxial cracking stress $(\mathrm{MPa})$ & 4.8 \\
Uniaxial crushing stress $(\mathrm{MPa})$ & 60 \\
\hline
\end{tabular}

If Equation (13) is satisfied, the material will crack or crush. However, the failure surface can be specified with a minimum of the two constants, ultimate uniaxial compressive and tensile strength [20].

\subsection{Modeling Impact of Boeing 747-200c Aeroplane}

The evaluation of an aeroplane crash on the outer NPP containment structure 
includes [21] global structural response such as (excessive structural deformations or displacements) and localized structural damage due to the effects of missile impact, such as penetration which lead to failure of a structural element.

The important parameters that affect the accident scenario of the impact of an aeroplane are velocity and impact angles of the aeroplane, mass, stiffness, size and location of the impact area.

Riera method [22] constructing a force time history to simulate an aeroplane crash impact has long been accepted for use in the accident analysis of an aeroplane impacts. This is an approximate method for constructing a force time history for a projectile striking a rigid wall based on a known distribution of mass and crushing characteristics of the projectile along the length [23]. The basic assumptions of the Riera method are the target is rigid; the axis of the missile is perpendicular to the target; the missile is separated into two regions, one being uncrushed and moving with velocity $(v)$ and the other region being crushed with zero velocity; all crushing takes place within a local region adjacent to the rigid target; and the crushing or material behavior of the missile is rigid perfectly plastic.

In addition, the mass of impact of an aeroplane which is adjacent to the rigid circular wall is crushed and brought to rest, resulting in a change of momentum. The resulting dynamic force is then applied to the wall along with the force required to crush the tip of an aeroplane structure [24]. The most dangerous impact is that of the aeroplane with maximum mass during impact. It is assumed that crushing force is calculated from Equation (14). Crushing force Re depends on the local crushing strength of fuselage [24].

$$
R e=A \sigma Y
$$

where: $A$ is effective area of crushing section and $\sigma Y$ is yielding stress of material.

The crushing force $\operatorname{Re}(x)$ induces instantaneous and homogenous deceleration $\mathrm{d} v / \mathrm{d} t$ in the remaining uncrushed part. If the total mass of the aeroplane is $M$ and the mass of the crushed part is $m(x)$ the deceleration and crushing force are related by Equation (15). It is assumed that there is no rebound of crushed part (soft impact) [24].

$$
[M-m(x)] \mathrm{d} v / \mathrm{d} t=-\operatorname{Re}(x)
$$

Equation (15) is an ordinary differential equation. By integrating speed, the distance $x(t)$ is function of time can be found and therefore the mass distribution $\mu(t)$ is function of time. Deceleration can be found by differentiating speed $v(t)$. The force that is acting on the target can be found by Riera's formula in Equation (16) [24].

$$
F=\operatorname{Re}(x)+\mu(x) v^{2}
$$

where, the aircraft is modeled by a stick with mass distribution $\mu(x)$ and crushing force $\operatorname{Re}(x)$, where $x$ is the distance along fuselage from aeroplane nose up to 
the current section that undergoes the crushing.

The impact load of the Boeing 747-200c was considered in this application concentrated at 16 nodes at an average distance of $30 \mathrm{~m}$ above the foundation level of the containment. The impact area of Boeing 747-200c aeroplane is assumed to be $36 \mathrm{~m}^{2}$ according to the maximum fuselage diameter of the aeroplane. In addition, the velocity of the Boeing 747-200c aeroplane is considered $968 \mathrm{~km} / \mathrm{hr}$. The represented load time curve for Boeing 747-200c is shown in Figure 10. The first peak load value as shown in Figure 10 is attributed to the crushing of the aeroplane fuselage, while the second peak value which is related to engines impacts [24].

\subsection{Cracking and Crushing in Concrete}

Cracks display circles at locations of cracking or crushing in concrete elements. Cracking is shown with a circle outline in the plane of the crack, and crushing is shown with an octahedron outline [20] if the crack has opened and then closed, the circle outline will have an $\mathrm{X}$ through it. Each integration point can crack in up to three different planes. The first crack at an integration point is shown with a red circle outline, the second crack with a green outline, and the third crack with a blue outline [20]. The two input strength parameters are ultimate uniaxial tensile and compressive strengths are needed to define the failure surface for the concrete. Consequently, a criterion for failure of the concrete due to a multi-axial stress state can be calculated according to William and Wranke [19].

\section{Analysis of Results}

The results consist of two parts that are related to each other. First part is to make a numerical simulation for RC containment of nuclear power plant using ANSYS software for modelling the external RC containment by subjecting it by an aeroplane load of Boeing 747-200c using Riera method in simulation of the load. In addition, the results of the simulation were analyzed according to magnitude and direction of displacement, velocity and acceleration. Moreover, the shape of the cracks was concluded from ANSYS simulation.

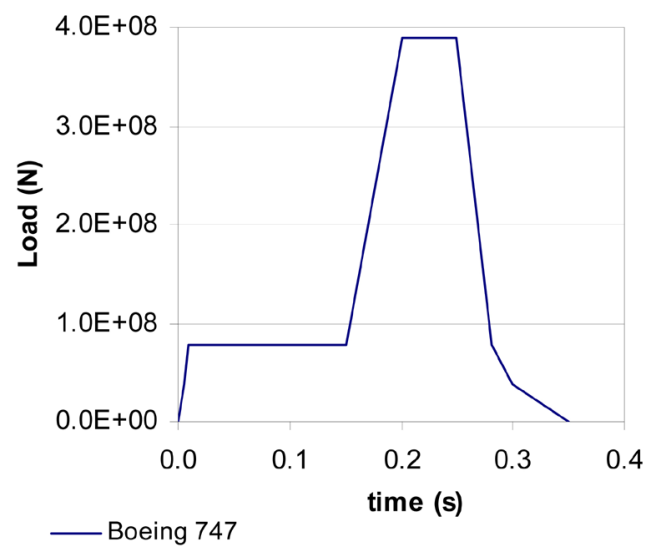

Figure 10. Load time curve for Boeing 747-200c at $269 \mathrm{~m} / \mathrm{sec}$ [21]. 
The second part of the analysis is to conduct an experimental program by exploring two elements away from the impact region from ANSYS simulation carry vertical crack in order to simulate it in the laboratory specimens. In addition, the vertical crack is simulated inside three laboratory specimens using failure criteria of concrete applied on the common nodes between two chosen elements from ANSYS software. Moreover, the three cracked laboratory specimens represent vertical cracks at different time of impact of an aeroplane. Furthermore, the fourth specimen represents uncracked specimen before the impact of an aeroplane. In addition, the dimension of the two elements in ANSYS are too large to simulate it in the laboratory, So, the method for construction of three experimental cracked specimens is to carry the vertical crack only as in ANSYS from failure criteria applied between the common nodes between two chosen elements at different time of impact and the cracked specimens contain a part from the two elements at which the crack is centered in the experimental specimens as in ANSYS between the common nodes. Moreover, the laboratory specimens carry the same reinforcement, inner steel liner plate thickness, concrete mix ingredients and the same thickness of the wall as the external RC containment in order to make a simulation for a part of real external RC conatinment. Two grids of sensors are distributed vertically and radially with equal spacing inside the core of the $\mathrm{RC}$ wall of the containment in order to make a structural health monitoring for full containment in real time. Sensors measure the variation in electrical resistivity between cracked and uncracked specimen in real time and Decimal Logarithm Resistivity Anisotropy (DLRA) gives an indication for the presence of the crack by dividing the resistivity in a direction to the other perpendicular direction in a continuous reading.

\subsection{Numerical Results}

The maximum displacement in the direction of impact loading on the outer containment occurred at the point of impact of an aeroplane which reached a value of $46.658 \mathrm{~mm}$ at time 0.2 second, due to impact of an aeroplane Boeing $747-200 \mathrm{c}$ at a speed of $269 \mathrm{~m} / \mathrm{sec}$ as shown in Figure 11.

The displacement, velocity and acceleration of RC containment in the direction of loading are maximum at the impact region and vanishes about $20 \mathrm{~m}$ in outer circumference direction from right and left hand side of impact region as shown in Figure 12.

The types of cracks at the containment are shear cracks which appear away from the impact region and at the fixation of the foundation with the wall are flexure cracks at the outer surface of the wall as shown in Figure 13. The region of impact of aeroplane on the external RC containment has locally failure in concrete element which makes spalling of concrete at this region of containment occurred locally to it, so it can be seen by naked eyes. The rest of RC containment has been fully intact. Two elements were chosen at the tension region away 


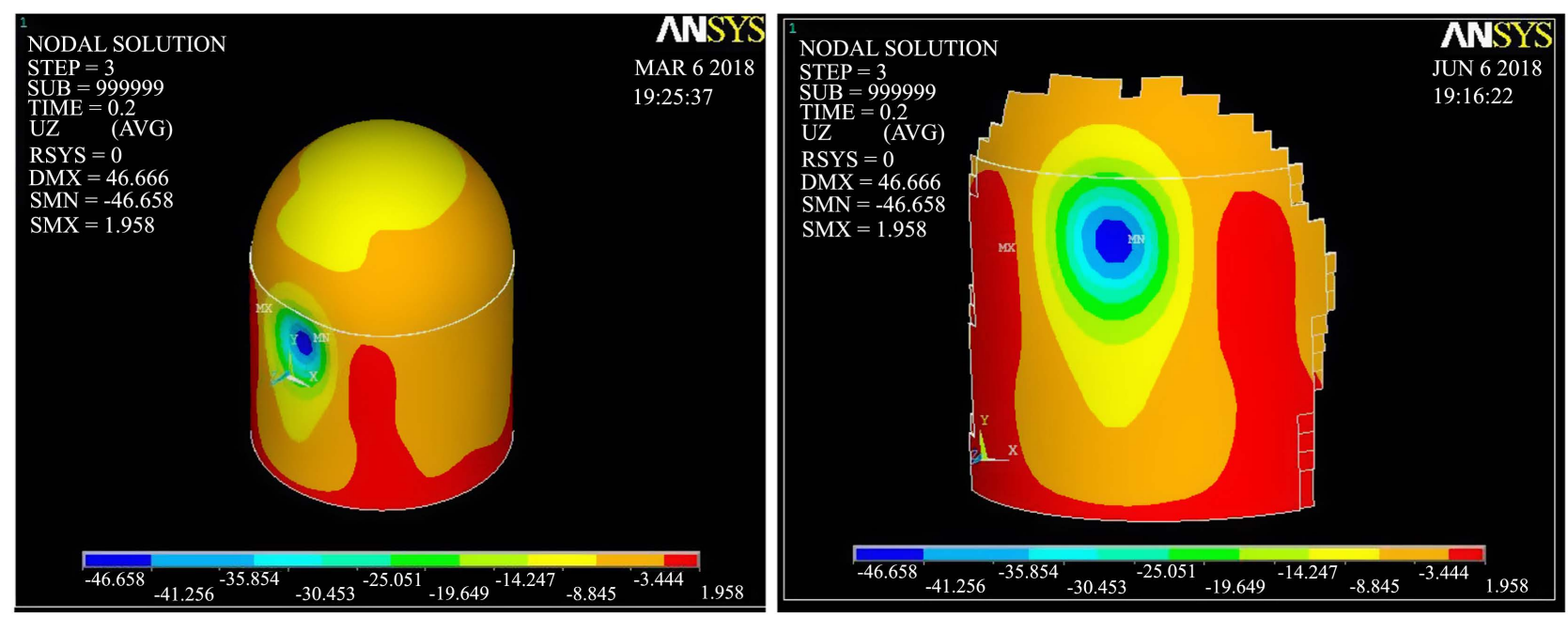

Figure 11. Maximum displacement in direction of loading at time of 0.2 second.

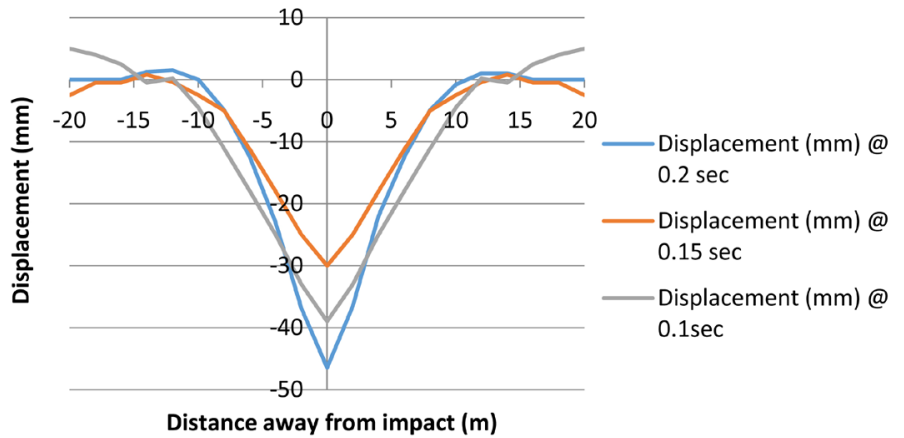

(a)

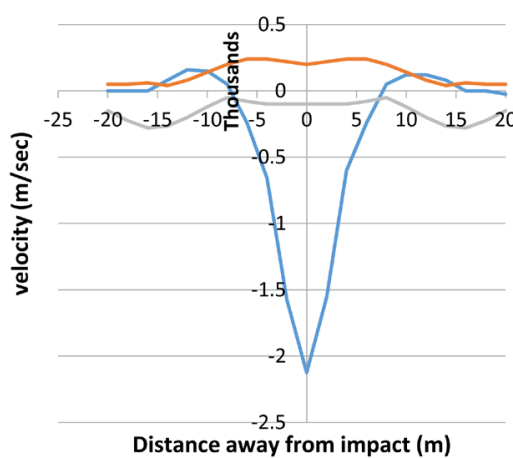

(b)

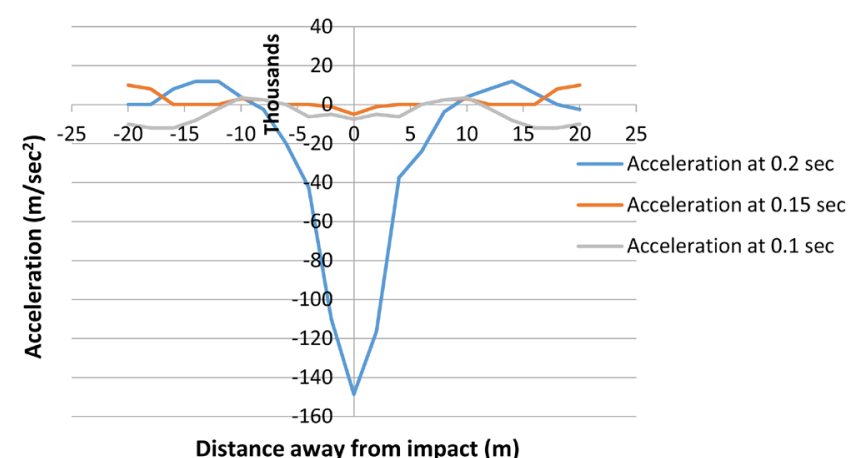

(c)

Figure 12. Displacement, velocity and acceleration for RC containment due to impact of Boeing 747-200c. (a) Displacement of RC containment in direction of loading at different time of impact; (b) Velocity of RC containment in direction of loading at different time of impact; (c) Acceleration of RC containment in direction of loading at different time of impact.

from the impact of an aeroplane Boeing 747-200c, this region come outside the plane of the RC containment which act as a rigid support, the chosen element carried vertical and horizontal cracks in direction perpendicular to horizontal tangential and vertical of cylinder respectively are as shown in Figure 13 and Figure 14. 


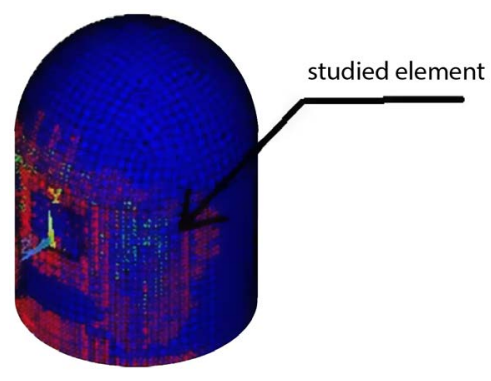

Figure 13. Cracking of containment due to impact of Boeing 747-200c aeroplane and the studied element away from the impact region.

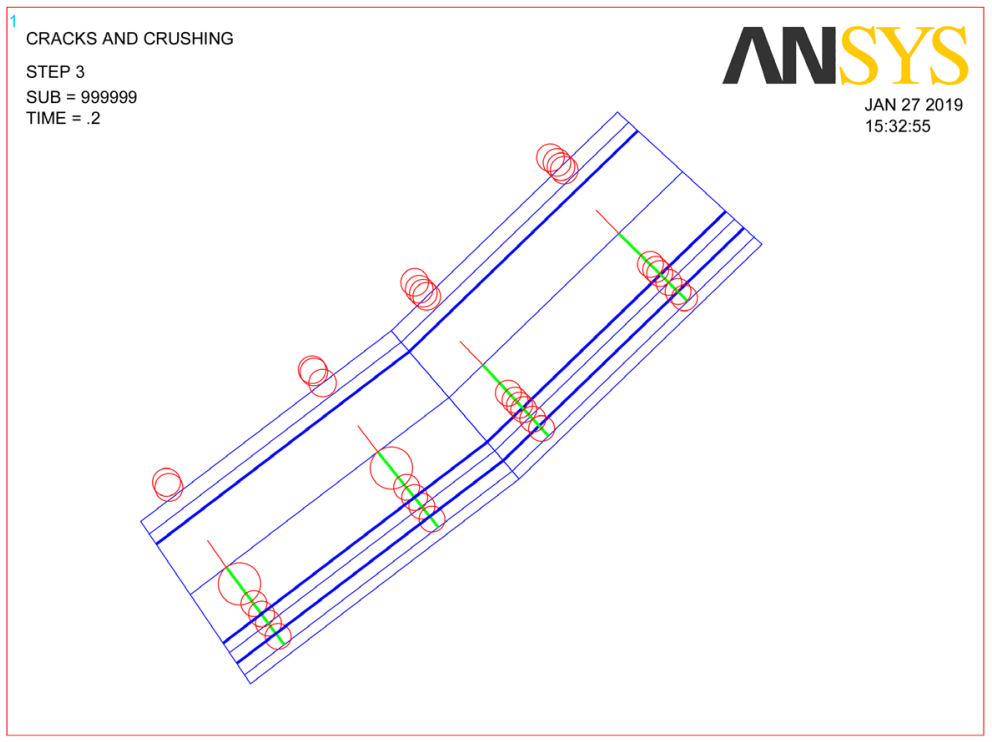

(a)

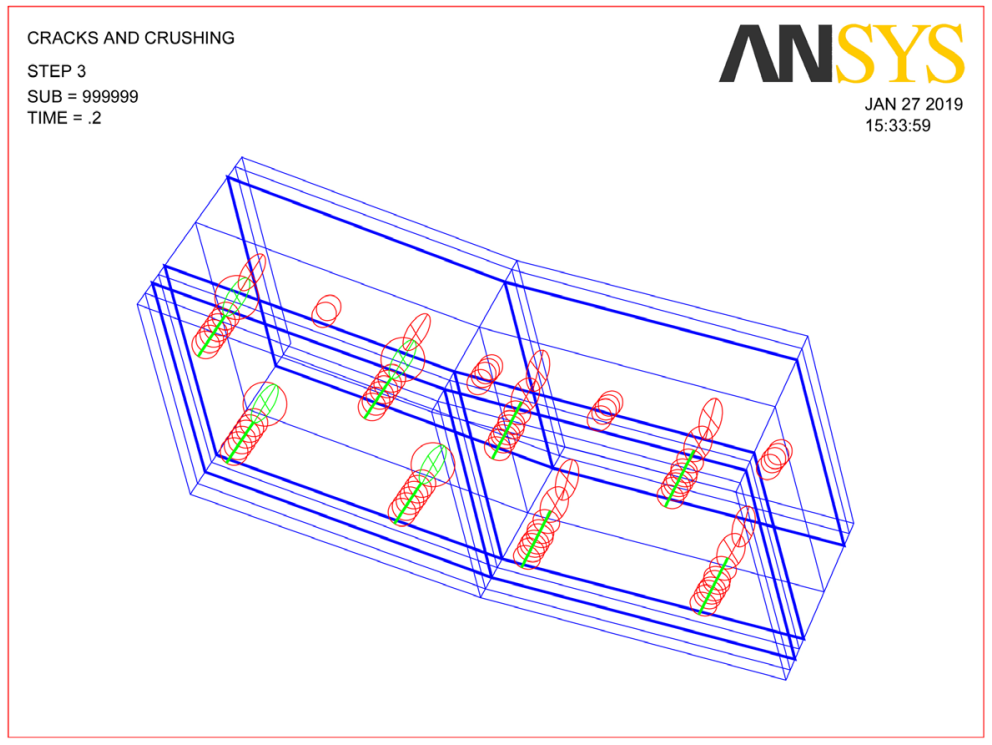

(b)

Figure 14. Cracked element away from impact region. (a) Plan of cracked element; (b) $3 \mathrm{D}$ cracked element. 


\subsection{Numerical -Experimental Simulation for Vertical Cracks}

Laboratory RC specimens were prepared by taking a part of two elements from ANSYS model as shown in Figure 15(a). Failure criteria of concrete which is built in ANSYS were applied on common nodes between two elements as shown in Figure 15(b) in order to trace the crack propagation length of the vertical crack with respect to the corresponding time of aeroplane impact.

The dimension of element size in ANSYS is $2.068 \mathrm{~m} \times 2.025 \mathrm{~m}$ with different thickness having acceptable aspect ratio as shown in Figure 15(b). A part from large two elements was taken to be suitable casting it in the laboratory with a

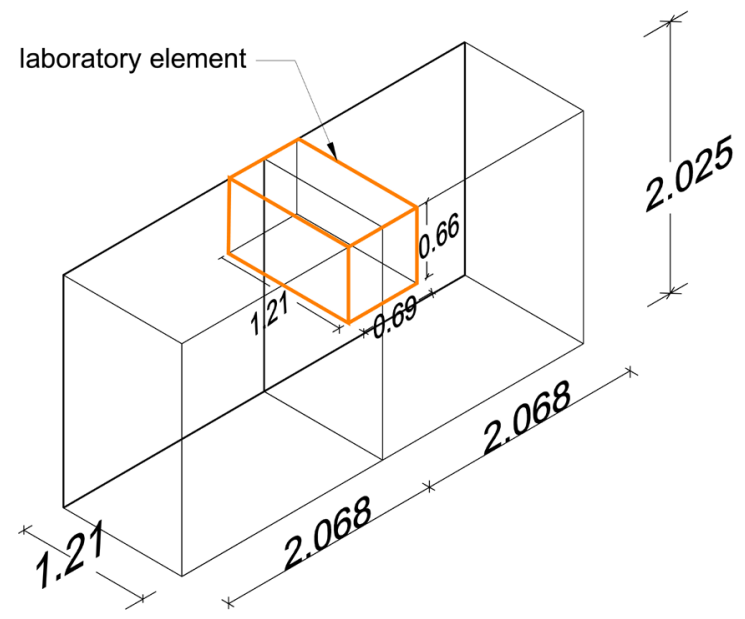

(a)

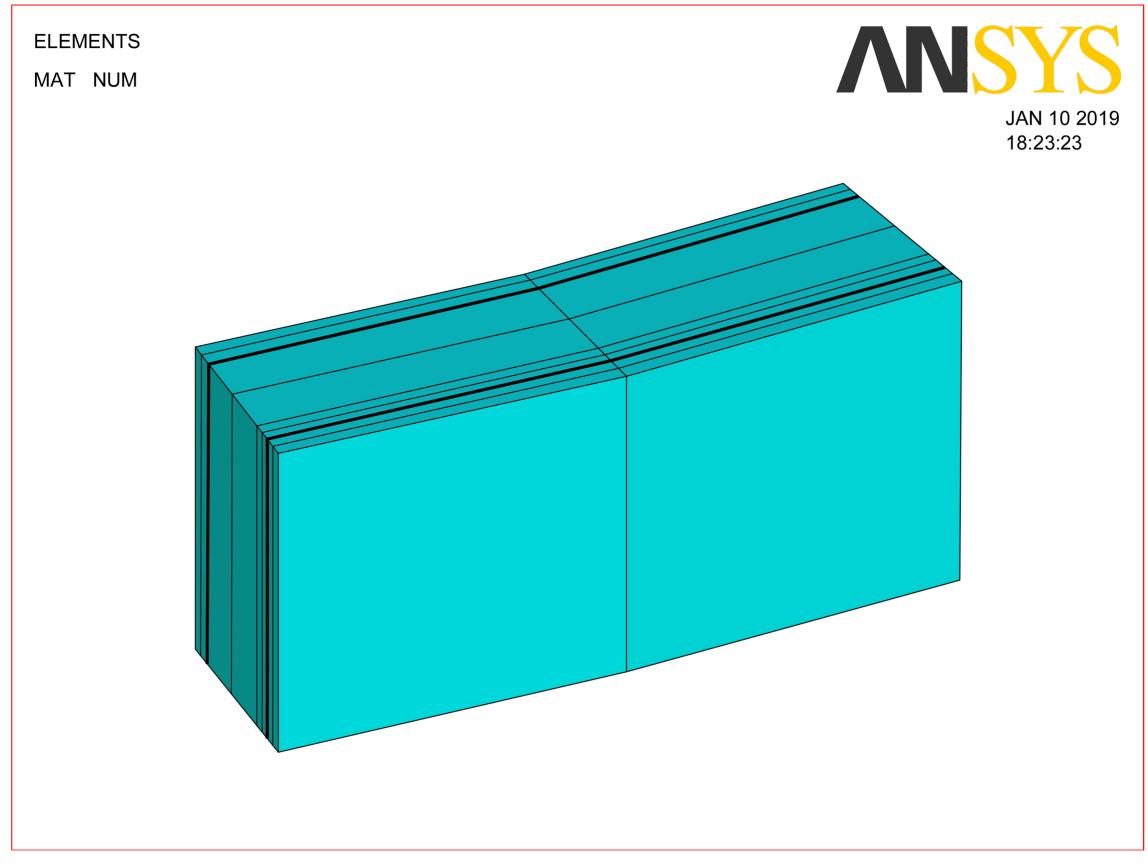

(b)

Figure 15. Two studied elements from ANSYS. (a) Laboratory element; (b) ANSYS element. 
dimension $(0.69 \mathrm{~m} \times 0.66 \mathrm{~m} \times 1.21 \mathrm{~m})$ in order to apply square inner electrical resistivity on 3 different cracked specimens which represent the cracks at different times (0.1-0.11-0.14) second of aeroplane impact, the other specimen is uncracked specimen which represents the specimen before the impact.

The length of the vertical crack was concluded from the domains of failure criteria of concrete applied on nodes of concrete in the studied elements in order to predict the length of vertical crack at different time of aeroplane impact as shown in Figure 16. Interpolation was made between the uncracked and cracked nodes by using $1^{\text {st }}$ principle elastic strain.

\subsection{Description for Experimental Program}

Each laboratory RC specimen carries eight red copper sensors of dimension (1 $\mathrm{cm} \times 1.5 \mathrm{~cm} \times 1 \mathrm{~cm}$ ). Sensors are drilled in 3 directions for fixation with formwork in laboratory in different directions. The spacing between the sensors configuration is $300 \mathrm{~mm}$, inside each laboratory specimen. Laboratory specimens included in its core two vertical square setup configurations were spaced at 300 $\mathrm{mm}$ between each other as shown in Figure 17 and Figure 18 according to

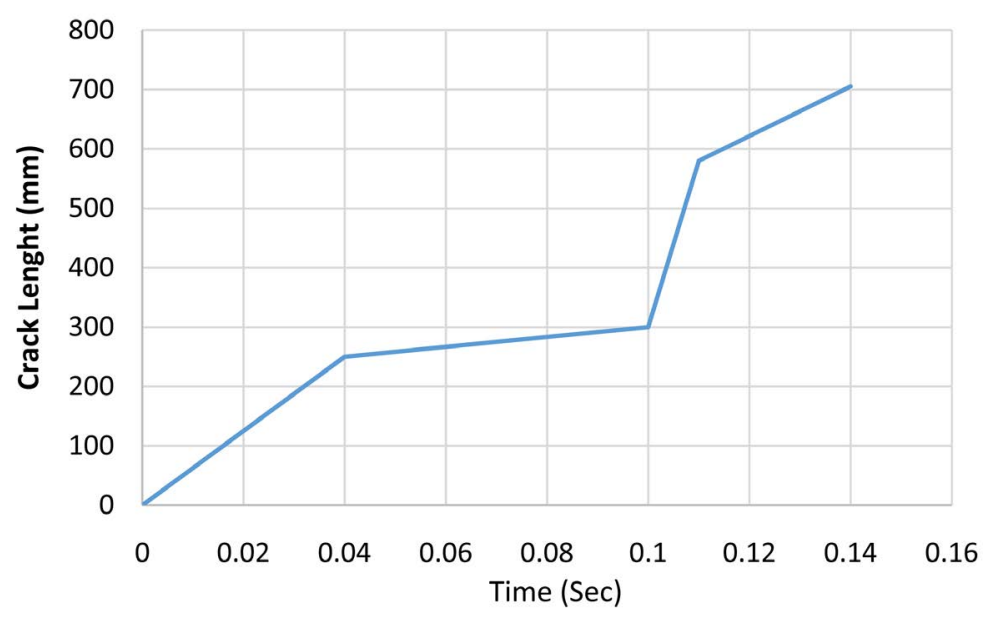

Figure 16. Length of vertical crack with respect to time of impact at nodes of studied element.

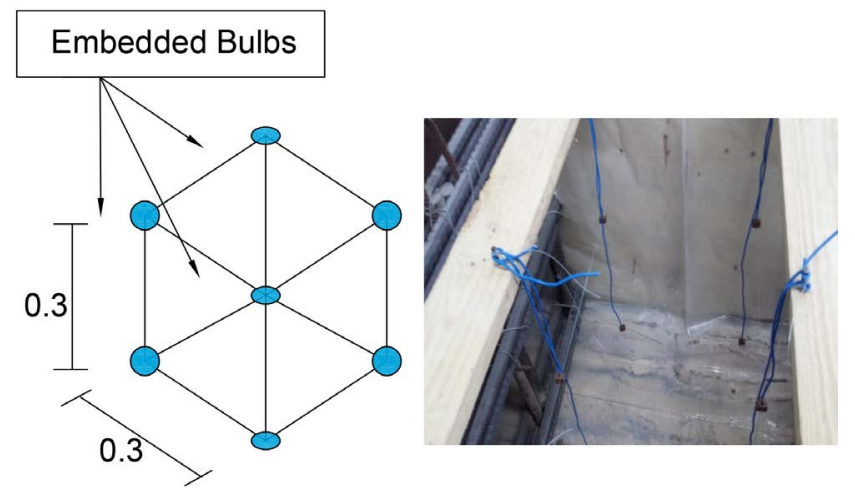

Figure 17. Three dimensional for sensors configuration. 


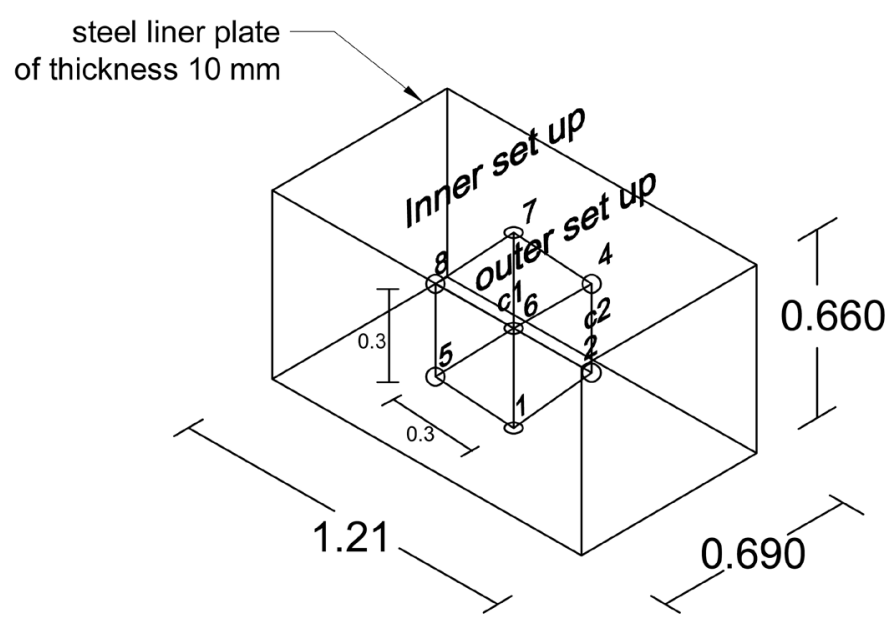

(a)

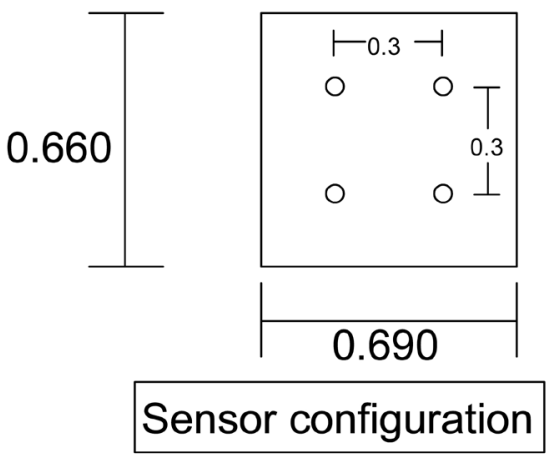

(b)

Figure 18. Uncracked specimen with embedded sensors. (a) Three dimensional for uncracked specimen; (b) Section elevation for setup of sensors.

Gowers and Millard [7]. The copper sensors are connected with copper wires of diameter $1.5 \mathrm{~mm}$ and at each end of wire removing $5 \mathrm{~cm}$ of plastic cover. One end of the wire is at the sensor and the other end is outside the concrete specimen in order to measure electrical resistivity. The Square Inner Electrical Resistivity Measurement (SIERM) was applied to the uncracked laboratory specimen as shown in Figure 17 and Figure 18.

Concrete mix had a constant water to cement ratio of 0.35 and a super plasticizer (SP) was used to maintain a constant slump of $10 \pm 2 \mathrm{~cm}$. Cement content $\left(450 \mathrm{~kg} / \mathrm{m}^{3}\right)$ and sand-to-total aggregate ratio $(40 \%)$ were adjusted for concrete mixture. The nominal maximum size of coarse aggregates was $40 \mathrm{~mm}$. Experimental results revealed that, the concrete mix containing hematite coarse aggregate along with $10 \%$ SF reaches the highest compressive strength values exceeding over $60 \mathrm{Mpa}$ according to Ouda [25] as shown in Table 2.

The laboratory concrete specimens its dimension are $(0.69 \mathrm{~m} \times 0.66 \mathrm{~m} \times 1.21$ $\mathrm{m})$ consists of a vertical and horizontal steel reinforcement in each side of specimen and inner steel liner plate are embedded at the back of the specimens as shown in Figure 19. 

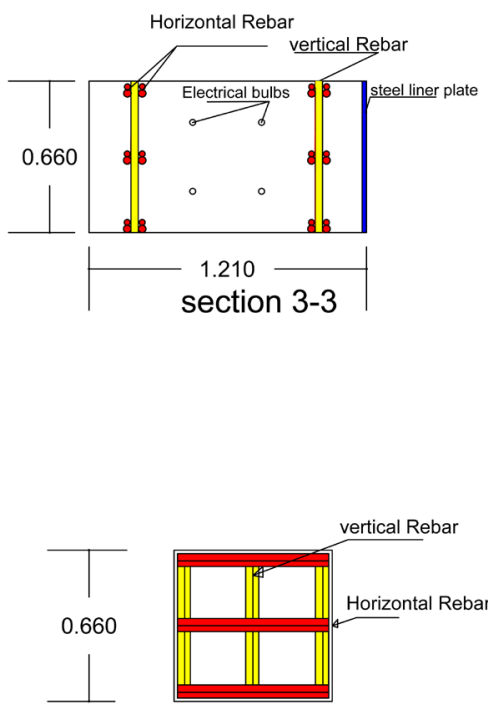

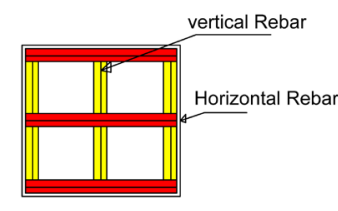

section 1-1
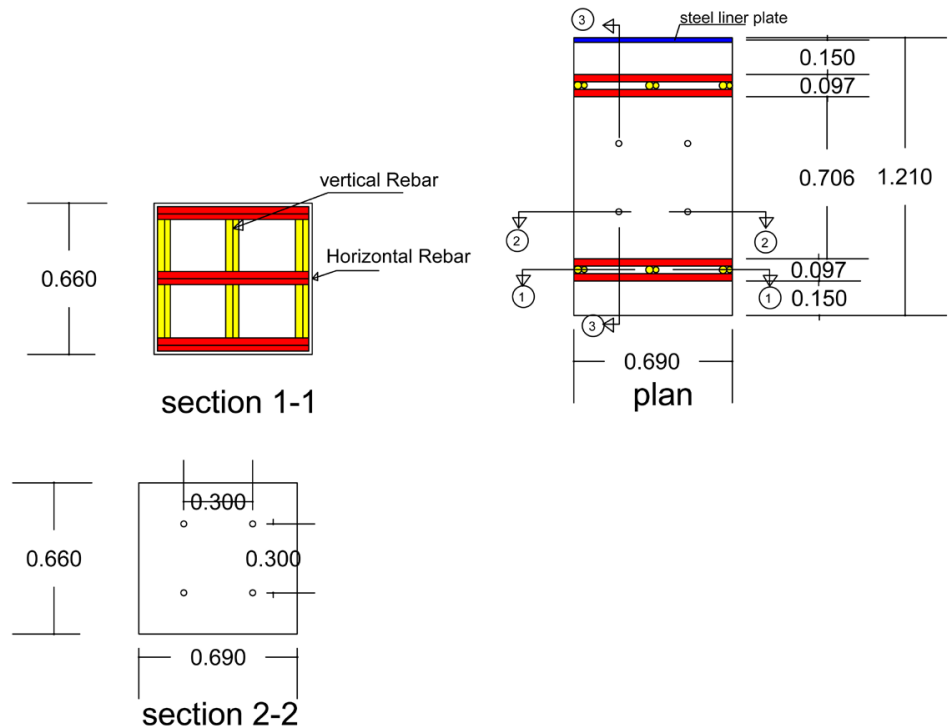

Figure 19. Details of reinforcement for specimens in different views.

Table 2. Concrete mix design for high performance concrete [25].

\begin{tabular}{cccccccc}
\hline Mix & $\begin{array}{c}\text { OPC } \\
\left(\mathrm{Kg} / \mathrm{m}^{3}\right)\end{array}$ & $\begin{array}{c}\text { Fine } \\
\text { Aggregate } \\
\left(\mathrm{Kg} / \mathrm{m}^{3}\right)\end{array}$ & $\begin{array}{c}\text { Hematite Coarse } \\
\text { Aggregate } \\
\left(\mathrm{Kg} / \mathrm{m}^{3}\right)\end{array}$ & $\begin{array}{c}\text { Silica } \\
\text { Fume } \\
\left(\mathrm{Kg} / \mathrm{m}^{3}\right)\end{array}$ & $\begin{array}{c}\text { Super } \\
\text { Plasticizer } \\
\left(\mathrm{Kg} / \mathrm{m}^{3}\right)\end{array}$ & $\begin{array}{c}\text { W/C } \\
\left(\mathrm{Kg} / \mathrm{m}^{3}\right)\end{array}$ \\
\hline Quantity & 450 & 909 & 1126 & 45 & 9.7 & 0.35 & 157.5 \\
\hline
\end{tabular}

The chosen element from ANSYS was cracked in vertical and horizontal direction locally. The three laboratory cracked specimens carry only vertical cracks. In the first vertical cracked specimen, the length of the crack inside the specimen is $300 \mathrm{~mm}$ away from the front configuration of sensors by $150 \mathrm{~mm}$ as shown in Figure 20(a). In the second vertical cracked specimen, the length of the crack inside the specimen is $580 \mathrm{~mm}$ which exceeds the first configuration of sensors by $130 \mathrm{~mm}$ as shown in Figure 20(b). In the third vertical cracked specimen, the length of the crack inside the specimen is $705 \mathrm{~mm}$ which exceeds the first configuration of sensors by $255 \mathrm{~mm}$ as shown in Figure 20(c). The vertical crack in the element can be resembled by a vertical plastic sheet of thickness 2 $\mathrm{mm}$ in the middle of $0.69 \mathrm{~m}$ dimension as shown in Figures 20(a)-(c).

\subsection{Experimental Program Results}

Measuring the square inner electrical resistivity in horizontal and vertical direction using Equation (17) [2]. 

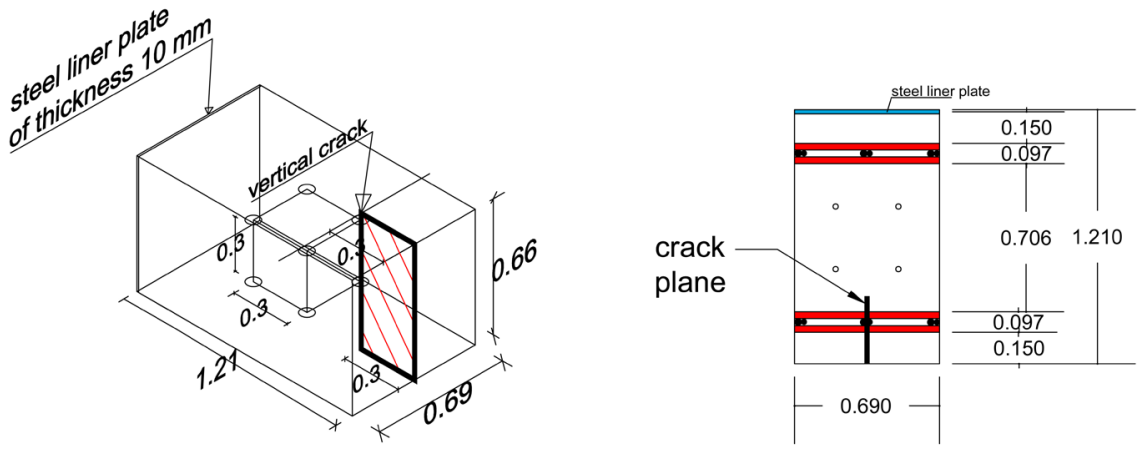

Plan

(a)
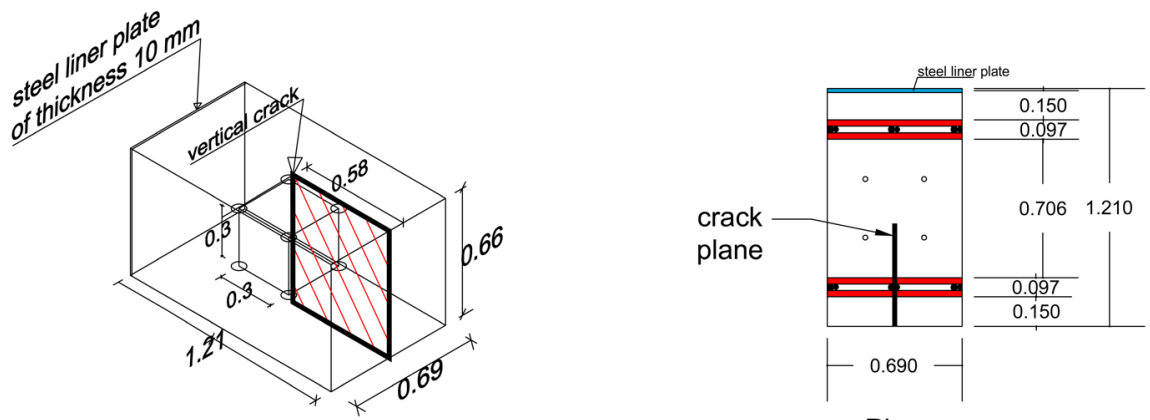

Plan

(b)
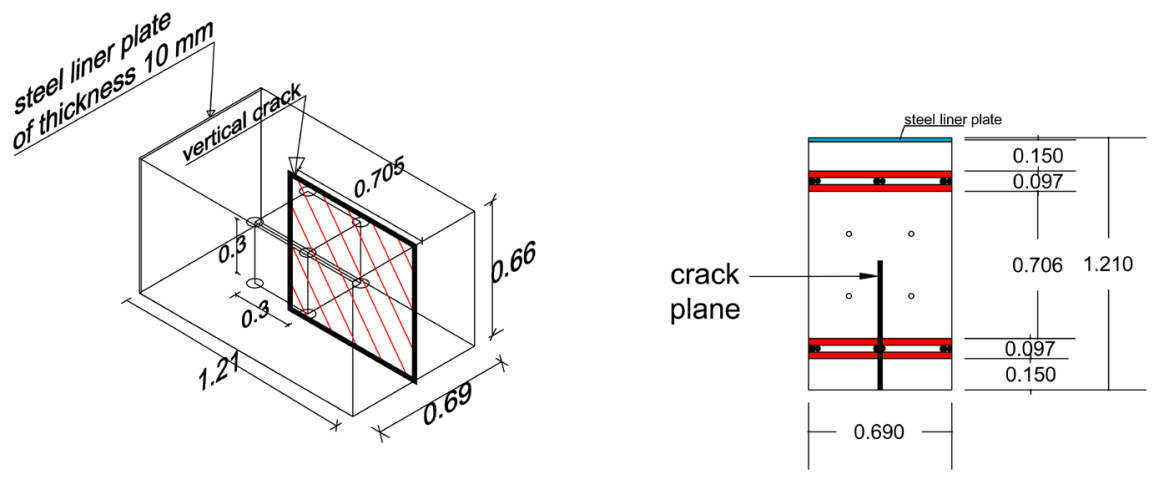

Plan

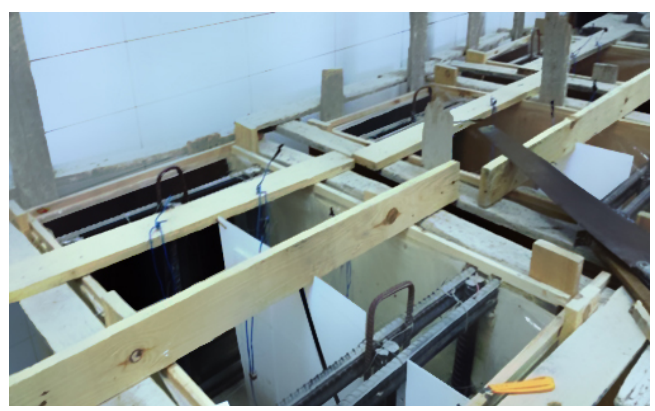

(c)

Figure 20. Shapes of vertical crack inside the laboratory specimens at different time of impact. (a) Cracked laboratory specimen at time $0.1 \mathrm{sec}$ for impact of an aeroplane; (b) Cracked laboratory specimen at time $0.11 \mathrm{sec}$ for impact of an aeroplane; (c) Cracked laboratory specimen at time $0.14 \mathrm{sec}$ for an impact of an aeroplane. 


$$
\rho=\frac{4 \times \Pi \times a \times R}{2-\sqrt{2}}
$$

where: $R$ : resistance of electrical current (ohms), a: spacing between sensors (m), $\rho$ : electrical resistivity (ohm's.m).

The measurement of electrical resistivity was taken once perpendicular to crack plane in horizontal direction, the other one parallel to the crack plane in vertical direction according to outer and inner square setup configuration inside the RC laboratory specimens with respect to time. The target for this research is structural health monitoring using (SIERM) technique inside the core of the RC wall. Two parameters were detected the damage (cracks). The first parameter used is the percentage change in electrical Resistivity between different cracked specimens and the uncracked specimen. The second parameter used is Decimal Logarithm Resistivity Anisotropy (DLRA) which gives a good indication for the presence and the direction of the crack inside the RC cylindrical wall.

It was concluded that the percentage change in electrical resistivity between the last cracked specimen of $705 \mathrm{~mm}$ crack length and the uncracked specimen in outer square setup reached a value of $413.33 \%$ as shown in Figure 21 (a) at which the direction of current is perpendicular to the crack plane. In addition, the percentage change of electrical resistivity between the last cracked specimen of crack length $705 \mathrm{~mm}$ and the uncracked specimen reached a value of $30 \%$ is shown in Figure 21(b), at which the crack is away from sensors for inner square setup.

The percentage change in electrical resistivity between the last cracked specimen of $705 \mathrm{~mm}$ crack length and the uncracked specimen in outer vertical square setup reached a value of $-76.67 \%$ is shown in Figure 21 (c), at which the direction of current is parallel to the crack plane, the resistivity is decreased according to Lataste et al. [1]. In addition, the percentage change in electrical resistivity between the last cracked specimen of $705 \mathrm{~mm}$ crack length and the uncracked specimen in inner vertical square setup reached a value of $-40 \%$ as shown in Figure 21(d), when the crack is away from sensors. Therefore, the percentage change in electrical resistivity is decreased in direction parallel to the crack plane according to Lataste et al. [1].

The second parameter used to detect the crack is the Decimal Logarithm Resistivity Anisotropy (DLRA) for concrete by dividing resistivity in direction perpendicular to the crack plane to the other measurement parallel to the crack plane and then calculating the DLRA from the equation. DLRA detected the presence and the direction of crack inside the RC specimen.

It was concluded that the maximum DLRA reached a value of 1.3 , when dividing resistivity in direction perpendicular to the crack plane to resistivity which is parallel to the crack plane in outer setup as shown in Figure 22(a). The DLRA in inner square setup at which the crack doesn't reach to the inner square setup configuration is too small compared to the outer square setup as shown in Figure 22(b) and reached a value of 0.335 


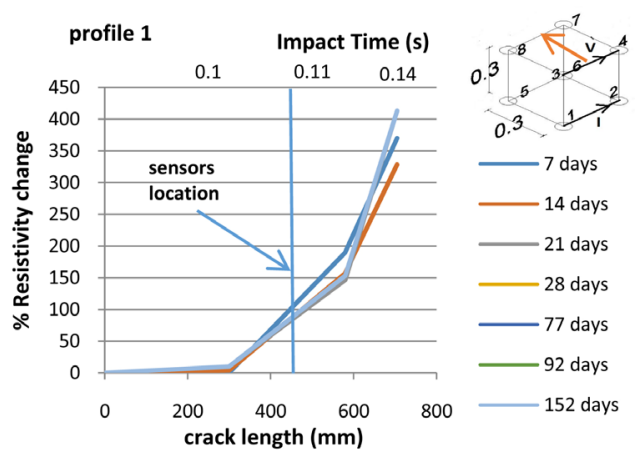

(a)

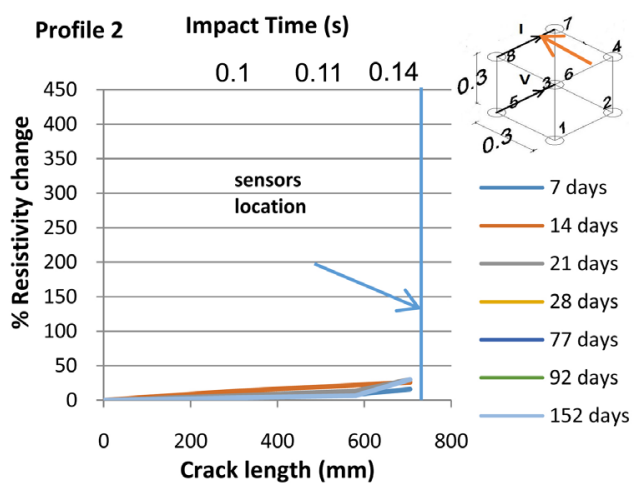

(b)

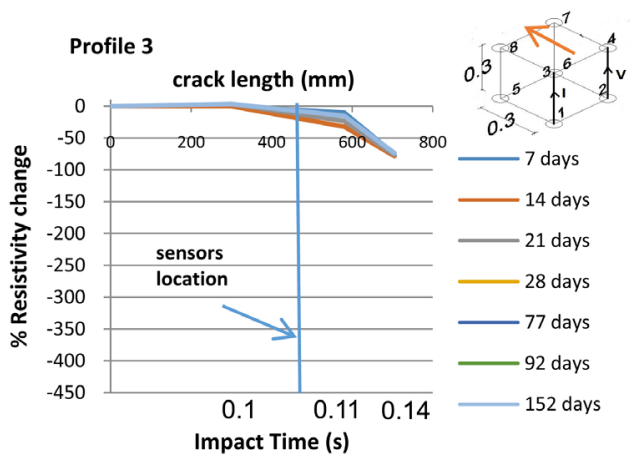

(c)

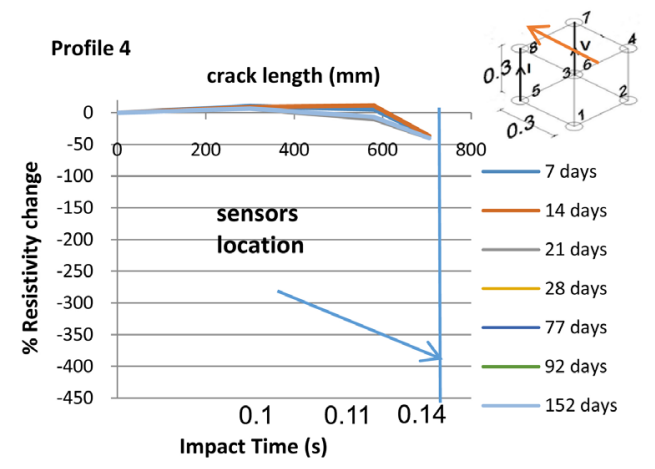

(d)

Figure 21. Different crack length and time from impact with respect to percentage of resistivity change at different setup configuration. 


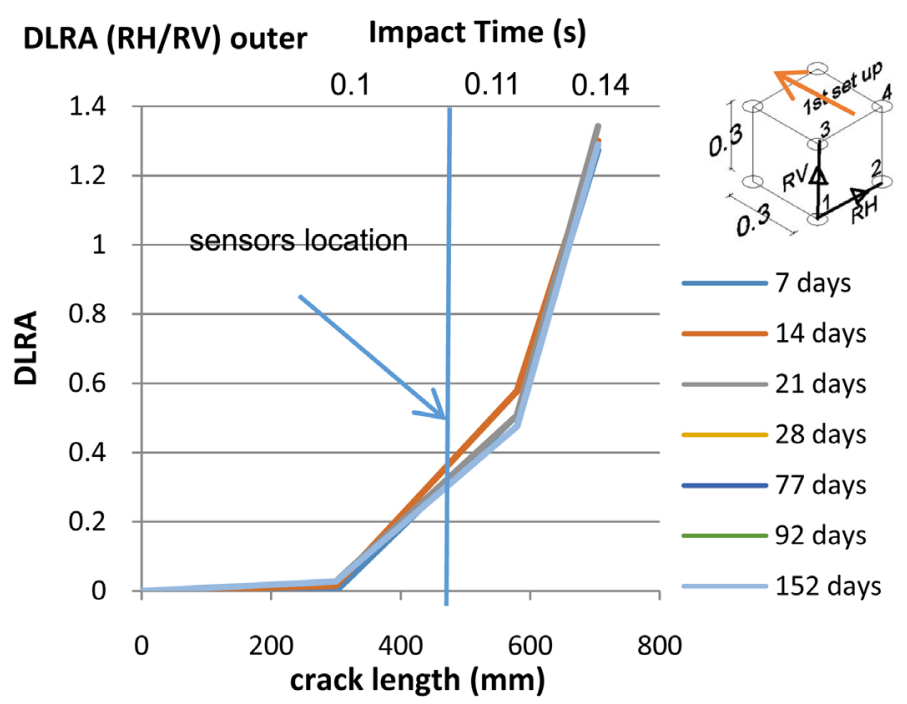

(a)

Impact Time (s)

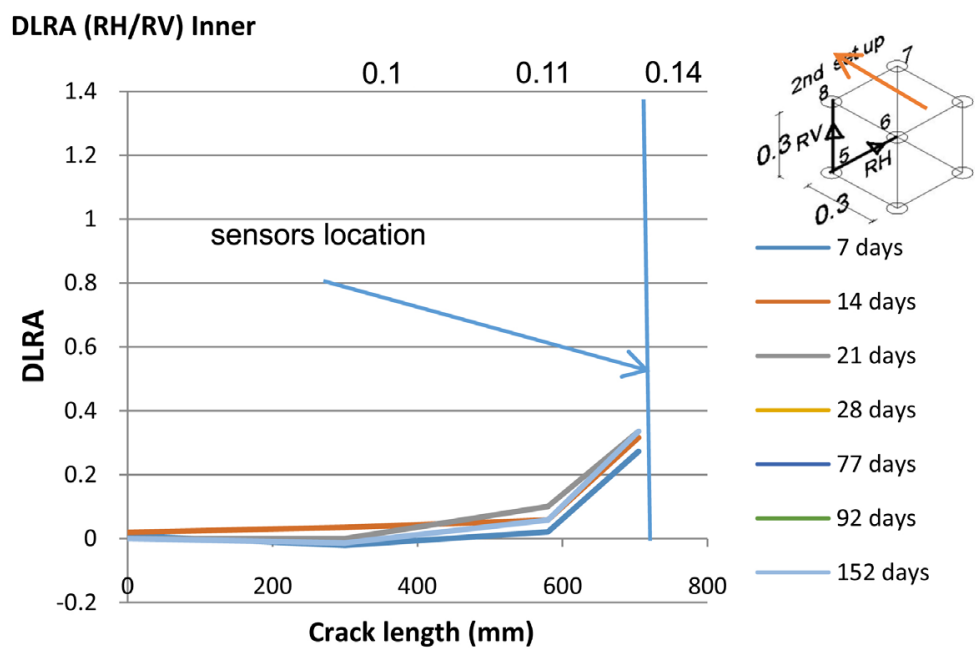

(b)

Figure 22. DLRA with respect to crack length and time from impact at different setup configuration.

\section{Conclusions and Recommendations}

The impact of an aeroplane on outer RC containment surface is considered as transient dynamic analysis. Nuclear concrete containment after the impact of an aeroplane Boeing 747-200c becomes globally stable and some elements have been damaged at the impact region only. Inner electrical resistivity is used as structural health monitoring technique in order to test typical RC containment wall and detect the cracks inside the core of concrete wall by using red copper sensors. There are two layers of sensors inside the wall of the containment and the distance between the two layers is $300 \mathrm{~mm}$ in order to measure the variation in electrical resistivity between the cracked and uncracked parts of the contain- 
ment. The copper sensors are distributed along the intermediate circumference of the wall and along the vertical direction of the wall spaced at $300 \mathrm{~mm}$ vertically and radially center to center between each sensor.

The crack propagation inside the studied element was deduced using the failure criteria of concrete which is built in ANSYS according to the domains of failure criteria. The two parameters which detect the presence of cracks inside concrete walls are the percentage of change in electrical resistivity between the cracked specimens and the uncracked specimen; the second parameter is Decimal Logarithm Resistivity Anisotropy (DLRA). It was observed that, when the current moves perpendicular to crack plane, the percentage change in electrical resistivity reached a value of $413.33 \%$ when it is compared to uncracked specimen, when the current moves in direction parallel to the crack plane the percentage change in electrical resistivity is decreased and reached a value of $-77.58 \%$ when it is compared to uncracked specimen. DLRA gives a jump of values and reached a value of 1.3 , when dividing the resistivity in the direction perpendicular to the crack plane to resistivity which is parallel to the crack plane. DLRA detected the presence of crack inside the wall and give indications for the directions of crack plane from its reading. The proposed technique for square inner electrical resistivity which consists of sensors inside the RC wall of NPPs successfully detects the variation in electrical resistivity between the cracked and uncracked parts of containment with respect to time continuously.

\section{Acknowledgements}

I would like to thank our professors Mohamed Ihab Elmasry and Nabil Hassan El Ashkar for their Support and help in this research and I would like to thank Arab Academy for Science, Technology and Maritime Transport for doing this experimental program in the heavy weight structural laboratory which is related to Construction and Building Engineering Department at Abu-Qir Campus.

\section{Conflicts of Interest}

The authors declare no conflicts of interest regarding the publication of this paper.

\section{References}

[1] Lataste, J.F., Sirieix, C., Breysse, D. and Frappa, M. (2003) Electrical Resistivity Measurement Applied to Cracking Assessment on Reinforced Concrete Structures in Civil Engineering. NDT \& E International, 36, 383-394. https://doi.org/10.1016/S0963-8695(03)00013-6

[2] Elmasry, M.I.S., ElAshkar, N.H. and Alasadi, M.F.A. (2012) Damage Identification in RC Beams Using Internal Electrical Resistivity Measurements. International Conference on Sustainable Design, Engineering, and Construction, Fort Worth, 7-9 November 2012, 801-809. https://doi.org/10.1061/9780784412688.096

[3] Elashkar, N.H., Elmasry, M.I.S. and Anndif, M.A.A. (2012) Damage Detection and Localization by Interpretation of Square Inner Electrical Resistivity Measurements. 
Sixth European Workshop on Structural Health Monitoring, Dresden, 3-6 July 2012, 1-10.

[4] Layssi, H., Ghods, P., Alizadeh, A.R. and Salehi, M. (2015) Electrical Resistivity of Concrete. Concrete International, 37, 41-46.

[5] Silva, P.C., Ferreira, R.M. and Figueiras, H. (2011) Electrical Resistivity as a Means of Quality Control of Concrete-Influence of Test Procedure. XII DBMC International Conference on Durability of Building Materials and Components, Porto, 12-15 April 2011, 1-8.

[6] Madhavi, T.C.H. and Annamalai, S. (2016) Electrical Conductivity of Concrete. ARPN Journal of Engineering and Applied Sciences, 11, 5979-5982.

[7] Gowers, K.R. and Millard, S.G. (1999) Measurement of Concrete Resistivity for Assessment of Corrosion Severity of Steel Using Wenner Technique. ACI Material Journal, 96, 536-541. https://doi.org/10.14359/655 https://www.concrete.org/publications/acimaterialsjournal.aspx

[8] Sengul, O. and Gjorv, O.E. (2009) Effect of Embedded Steel on Electrical Resistivity Measurements on Concrete Structures. ACI Materials Journal, 106, 11-18.

https://doi.org/10.14359/56311

[9] Shahroodi, A. (2010) Development of Test Methods for Assessment of Concrete Durability for Use in Performance-Based Specifications. Masters of Applied Science (M.A.Sc.) Thesis, University of Toronto, Toronto.

[10] Polder, R.B. (2000) RILEM TC 154-EMC: Electrochemical Techniques for Measuring Metallic Corrosion. Materials and Structures, 33, 603-611. https://doi.org/10.1007/BF02480599

[11] Ferreira, R.M. and Jalali, S. (2010) NDT Measurements for the Prediction of 28-Day Compressive Strength. NDT \& E International, 1, 55-61.

https://doi.org/10.1016/j.ndteint.2009.09.003

[12] Morris, W., Moreno, E.I. and Sagues, A.A. (1996) Practical Evaluation of Resistivity of Concrete in Test Cylinders Using a Wenner Array Probe. Cement and Concrete Research, 26, 1779-1787. https://doi.org/10.1016/S0008-8846(96)00175-5

[13] McCarter, W.J., Starrs, G., Kandasami, S., Jones, R. and Chrisp, M. (2009) Electrode Configuration for Resistivity Measurements on Concrete. ACI Materials Journal, 106, 258-264. https://doi.org/10.14359/56550

https://researchportal.hw.ac.uk/en/publications/electrode-configurations-for-resisti vity-measurements-on-concrete

[14] Mehta, K.P. and Monteiro, P.J. (2006) Concrete Microstructure, Properties, and Materials. Electronic Book, McGraw-Hill Education, London, 529-531.

[15] ASCE Standard 58 (1980) Structural Analysis and Design of Nuclear Plant Facilities.

[16] Czerniewski, S. (2009) The Feasibility of Modern Technologies for Reinforced Concrete Containment Structures of Nuclear Power Plants. Report of Master Science, KANSAS State University, Manhattan.

[17] Salman, W.D. (2015) Nonlinear Behavior of Reinforced Concrete Continuous Deep Beam. International Journal of Engineering Research \& Technology (IJERT), 4, 2278-2281. https://doi.org/10.17577/IJERTV4IS040460

[18] Teh Hu, H. and Liang, J.I. (2015) Ultimate Analysis of BWR Mark III RC Containment Subjected to Internal Pressure. Nuclear Engineering and Design, 195, 1-11. https://doi.org/10.1016/S0029-5493(99)00163-6

[19] William, K.J. and Warnke, E.P. (1974) Constitutive Model for the Tri-Axial Beha- 
viour of Concrete. IABSE Reports of the Working Commissions, Bergamo.

[20] ANSYS12.1 (2012) Theory Reference Manual.

[21] Forasassi, G. and Lofrano, R. (2010) Preliminary Analysis of an Aircraft Impact. A Report of Ricerca di Sistema Elettrico.

[22] Riera, J.D. (1968) On the Stress Analysis of Structures Subjected to Aircraft Impact Forces. Nuclear Engineering Design, 8, 415-426. https://doi.org/10.1016/0029-5493(68)90039-3

[23] James, R.J. and Rashid, J.Y.R. (2005) Severe Impact Dynamics of Reinforced Concrete Structures. 6th European Conference on Structural Dynamics, Paris, 4-7 September 2005, 1-7.

[24] Iliev, V., Georgiev, K. and Serbezov, V. (2011) Assessment of Impact Load Curve of Boeing 747-400. MTM Virtual, 1, 22-25.

[25] Ouda, A.S. (2014) Development of High-Performance Heavy Density Concrete Using Different Aggregates for Gamma-Ray Shielding. Progress in Nuclear Energy, 79, 48-55. https://doi.org/10.12989/amr.2014.3.2.061 